\title{
Blends lexicais e neologismos: alguns conceitos e problematizações
}

Lexical blends and neologisms:
some concepts and
problematizations

Rafael PREARO-LIMA (UNESP/IFSP) rprearo@hotmail.com

Recebido em: 22 de jan. de 2019. Aceito em: 14 de jun. de 2019.
PREARO-LIMA, Rafael. Blends lexicais e neologismos: alguns conceitos e problematizações. Entrepalavras, Fortaleza, v. 9, n. 3, p. 38-56, setdez/2019.

Resumo: O processo de formação neológica é um indicativo da dinamicidade das línguas: à medida que a sociedade muda, novas palavras são necessárias para descrever tais mudanças. Tendo isso em mente, o objetivo deste trabalho é observar a formação de neologismos a partir de um processo de formação de palavras, o blend lexical (ou cruzamento vocabular). Para isso, primeiramente apresentaremos e discutiremos alguns conceitos do campo de estudos lexicológicos a respeito de neologismos e de como identificá-los. Depois, apresentaremos o conceito de blends lexicais e como estes são formados. Em seguida, analisaremos ocorrências de blends lexicais entre a palavra "crente" e outras palavras, discutindo se essas ocorrências podem ou não ser consideradas como neologismos. Tais blends foram coletados a partir de postagens da rede social Twitter e selecionados conforme o significado pudesse ser evidenciado a partir de seu uso. Como base teórica, usaremos as definições de neologismos a partir de Rey (1976), Alves (1996, 2001, 2007), Rio-Torto (2007) e Cano (2007), além de considerarmos os estudos de Gonçalves (2003, 2006, 2012) a respeito de blends lexicais. A partir das atuais definições do conceito de neologismo, a análise aponta a dificuldade de precisar os blends lexicais 
como um fenômeno neológico, indicando a necessidade de aprofundamento teórico para melhor delimitar a identificação de tal fenômeno.

Palavras-chave: Lexicologia. Blend lexical. Neologismo.

Abstract: The process of neology formation shows how dynamic languages are: as society changes, new words are necessary to describe these changes. Having that in mind, the goal of this paper is to observe the formation of neologisms based on a process of word formation known as lexical blends. To do so, firstly we will present and discuss some concepts in the lexicological field regarding neologisms and how to identify them. After that, we will present the concept of lexical blends and how these are formed. Then, we will analyze occurrences of lexical blends between the word "crente" ("believer", namely, those of Christian faith) and other words, discussing whether these occurrences may be considered as neologisms. Such blends have been collected from the social media Twitter and selected as their meaning could be evident based on their use. For our theoretical basis, we will use the definitions of neologisms based on Rey (1976), Alves (1996, 2001, 2007), Rio-Torto (2007) and Cano (2007), besides considering the studies of Gonçalves (2003, 2006, 2012) regarding lexical blends. Based on the current definition of neologisms, the analysis indicates it is difficult to determine lexical blends as a neologism, indicating the need to deepen the theoretical discussion to set clearer boundaries regarding the identification of such phenomenon.

Keywords: Lexicology. Lexical blend. Neologism.

\section{Considerações iniciais}

A neologia enquanto processo contínuo é um indicativo da dinamicidade das línguas, tendo no léxico um lugar de transformação constante. Ao acompanhar o movimento e as mudanças na/da sociedade, a língua também muda, em uma relação entrelaçada entre língua e sociedade em que uma incide sobre a outra e vice-versa. A cada micro/ macro mudança social, é preciso (re)nomear, (re)categorizar e/ou (re) pensar formas para que essas mudanças sejam exprimíveis. Nos casos, por exemplo, de mudanças associadas à produção de conhecimentos, costuma-se observar a criação de formas lexicais para dar conta de cada novo evento, descoberta e/ou avanço científico, como as inúmeras palavras e expressões associadas à informática e ao mundo virtual necessárias para nomear aquilo antes inexistente (termos como resetar, dar um like, tuitar, printar, 4G, wi-fi...).

Nesse processo neológico contínuo, nota-se que uma das características do português brasileiro é a possibilidade de se obter, por meio de processos diversos, novas palavras a partir de outras já existentes (por exemplo, blogue, blogueiro, blogar). Isso torna o sistema linguístico mais dinâmico no sentido de menos "formas diferentes" precisarem ser acessadas, diferentemente do que aconteceria se para cada novo gesto de nomeação fosse preciso uma forma nova e distinta das outras. 
V. 9 (3) $38-56$ set-dez 2019

A respeito da possibilidade de haver palavras diferentes para cada mudança (de classe gramatical, por exemplo, ou para cada acréscimo semântico), Basílio (2004) afirma que a quantidade de palavras necessárias para compor nosso vocabulário básico seria tão grande que faria da língua um sistema de comunicação menos eficiente. Por isso, pela dificuldade que teríamos de captar, memorizar e acessar diferentes formas lexicais para diversos contextos e situações é que emerge o motivo pelo qual há, muitas vezes, novas formas lexicais a partir de outras. A autora prossegue ao explicar que:

\begin{abstract}
a razão por que formamos palavras é a mesma razão por que formamos frases: o mecanismo da língua sempre procura atingir o máximo de eficiência, o que se traduz num máximo de flexibilidade em termos de expressão simultaneamente a um mínimo de elementos estocados na memória. É essa flexibilidade que nos permite contar com um número gigantesco de elementos básicos de comunicação sem termos que sobrecarregar a memória com esses mesmos elementos. (BASÍLIO, 2004, p. 10).
\end{abstract}

Desse modo, a combinação a partir de diferentes formas conhecidas (os "elementos mínimos estocados na memória" a que Basílio se refere, como radicais e afixos) possibilita a formação de uma quantidade praticamente infindável de novas palavras e, a partir delas, novos sentidos. Gonçalves (2012), ao analisar tendências de formação de palavras no português brasileiro, confirma a existência dessa flexibilidade a partir de um número mínimo de elementos. Segundo o autor, novas palavras cunhadas a partir de padrões já estabelecidos na língua são muito mais frequentes que, por exemplo, palavras exnihilo (criadas "do nada"), formas raras sem a ativação de quaisquer processos morfológicos.

Partindo dessa problematização, decidimos observar a formação neológica sob a perspectiva de um processo de formação de palavras que pode ser produtivo nesse aspecto. Especificamente, direcionaremos nosso olhar para os blends lexicais, que, de acordo com Gonçalves (2012), é um dos processos de formação de palavras em que os neologismos são abundantes no português contemporâneo. Para isso, analisaremos o processo de blend lexicais tendo como foco a análise a partir da palavra crente e, partir dela, discutiremos noções teóricometodológicas a respeito de neologismos para sabermos se esses blends apresentados podem (ou não) ser considerados como tais. 


\section{Procedimentos metodológicos}

Para o desenvolvimento deste trabalho, traremos algumas noções a respeito do conceito e da identificação de neologismos, fazendo considerações a respeito das dificuldades que a noção suscita. Semelhantemente, apresentaremos o conceito de blend lexical e seu processo de formação, que auxiliarão na compreensão dos casos discutidos posteriormente. Em seguida, analisaremos diferentes exemplos de blends lexicais entre o termo crente e outras palavras, discutindo se seriam (ou não) considerados como neologismos.

Ressaltamos que a escolha da palavra crente para esta pesquisa não ocorreu de modo aleatório, dado que este trabalho é parte de um projeto maior em desenvolvimento, cujo objetivo é investigar estereótipos de evangélicos a partir de uma análise discursiva, partindo dos pressupostos teórico-metodológicos da Análise do Discurso francesa. Desse modo, este trabalho serve de base para estudos ainda a serem desenvolvidos. De qualquer forma, outros exemplos poderiam ter sido usados para a discussão a respeito de blends lexicais serem ou não casos de neologismos sem que, no entanto, houvesse prejuízo quanto às reflexões aqui apresentadas.

A fim de verificar a existência de tais ocorrências, pesquisamos na rede social Twitter, por meio de seu mecanismo de busca, postagens com blends entre a palavra crente e outras palavras. À medida que encontrávamos tais ocorrências, as postagens foram selecionadas de modo a evidenciar, em maior ou menor grau, o significado a partir de seu uso. Assim, apesar da grande quantidade de material disponível nessa rede social, e dada a extensão deste trabalho, decidimos disponibilizar apenas os exemplos mais representativos.

É importante destacarmos a decisão de reproduzir as postagens como elas se encontram no Twitter para que sejam mantidas suas características, evitando, dessa forma, a alteração de detalhes expressivos durante a transcrição (uso de letras maiúsculas, repetições, desvios da norma padrão etc.). Parte dessa decisão também está no fato de mantermos as datas das postagens ${ }^{1}$, de modo a evidenciar que o uso de cada blend encontrado não se restringia a um período específico, mas abrangia um período em torno de cinco anos ou mais, um indicativo de que circulariam há um tempo entre falantes do português brasileiro.

${ }^{1}$ Sobre a datação, as postagens sem a marcação de ano referem-se a 2018, quando este trabalho foi desenvolvido. 
v. 9 (3) $38-56$ set-dez 2019

Também é relevante destacarmos que, por motivos de ética na pesquisa, decidimos pela supressão da identificação dos autores das postagens utilizadas.

\section{A respeito de neologismos e blends lexicais}

Apresentamos, a seguir, algumas concepções a respeito de neologismos e de sua identificação, sem, no entanto, a pretensão de esgotarmos o assunto ou de solucionarmos as dificuldades teóricometodológicas suscitadas. Nosso objetivo, porém, é discutir e problematizar tais posições teóricas. Em seguida, apresentaremos a definição e a formação de blends lexicais por acreditarmos, no que se refere à discussão a respeito da formação neológica no/do português brasileiro, ser um processo produtivo.

O linguista francês Louis Guilbert realizou diversos estudos sobre a neologia, que diz respeito aos fenômenos novos que atingem uma língua (cf. ALVES, 1996, 2001). Para ele, a neologia no nível lexical é definida como "a possibilidade de criação de novas unidades lexicais, em razão das regras de produção incluídas no sistema lexical" (GUILBERT, 1975, p. 31 apud ALVES, 2001, p. 25). Outro linguista, o canadense Jean-Claude Boulanger, definiu o neologismo como "uma unidade lexical de criação recente, uma nova acepção de uma palavra já existente, ou ainda, uma palavra recentemente emprestada de um sistema linguístico estrangeiro e aceito na língua [...]" (BOULANGER, 1979, p. 65-66 apud ALVES, 2001, p. 25).

Apesar de difundidas e, até certo ponto, bem aceitas, essas definições suscitam algumas dúvidas, principalmente quanto à datação. Em que exatamente consiste uma "nova unidade lexical", uma "criação recente", uma "nova acepção" ou ainda "uma palavra recentemente emprestada"? Qual a abrangência temporal para que uma unidade lexical seja considerada como "recente" ou "nova"? Não fica claro nessas concepções qual o escopo temporal necessário para que uma palavra seja considerada como um neologismo.

Esse não é um questionamento recente. Já na década de 1970, Alain Rey (1976) problematizava sobre a constituição de uma unidade lexical como "nova". A partir de algumas definições de neologismo, o autor afirma ser possível: 
lexical, dentro de um código linguístico". Aparentemente coerente, esse conceito coloca três tipos de dificuldades. Primeiramente, de qual unidade se trata? Em seguida, de qual novidade? Por fim, qual definição de código (ou de sistema) é a mais pertinente e quais são as relações entre a unidade neológica e o todo onde ela se manifesta? (REY, 1976, p. 4, acréscimo nosso). ${ }^{2}$

Para tentar lidar com esses questionamentos, estudiosos da Lexicologia sugerem alguns procedimentos metodológicos. Citamos Rio-Torto (2007), que explica que, para verificar se uma palavra pode (ou não) ser considerada como neológica, deve-se tomar um conjunto de fontes de uma determinada época como universo de exclusão (ou corpus de exclusão). Por uma razão de praticidade, acrescenta a autora, utiliza-se um dicionário de referência, ou um conjunto de dicionários, para tal tarefa. O fato da palavra não ter sido dicionarizada é, assim, um indicativo de um neologismo. Alves (2007, p. 78) corrobora ao afirmar que:

o parâmetro mais adotado para a consideração do caráter inovador dessas palavras, denominadas neologismos, tem sido o do córpus de exclusão lexicográfico, constituído por um conjunto de dicionários que atua como filtro para a determinação, ou não, do caráter neológico da unidade lexical sob análise.

De fato, a constituição de um universo de exclusão a partir de dicionário(s) representativo(s) pode ser uma alternativa para determinar se certa unidade lexical é ou não neológica. Ainda assim, o uso de um corpus de exclusão não impede o pesquisador de se deparar com algumas dificuldades. Cano (2007), por exemplo, explica que, por maior que seja um corpus de exclusão, ele está sujeito às limitações dos dicionários, como a ausência de critérios para que derivados sejam inseridos nas entradas de unidades lexicais. Além disso, visto que nem todas as palavras são dicionarizadas, como precisar se a ausência em dicionários indica um neologismo de fato ou a decisão, qualquer que seja, de lexicógrafos de omitir esse registro? Tomemos o caso de algumas gírias, expressões idiomáticas e/ou regionalismos que, apesar de seu uso corrente e prolongado na língua, não são tidos como neologismos e tampouco costumam ser dicionarizados.

\footnotetext{
${ }^{2}$ Tradução livre de: "aborder la question en situant le néologisme comme : 'une unité nouvelle, de nature lexicale, dans un code linguistique défini.' Apparemment cohérent, ce concept pose trois types de difiicultés. Premièrement, de quelle unité s'agit-il ? Puis, de quelle nouveauté ? Enfin, quelle définition du code (ou du système) est la plus pertinente, et quels sont les rapports entre l'unité néologique et l'emsemble où elle se manifeste ?"
} 
v. 9 (3) $38-56$ set-dez 2019

Indo além, como proceder nos casos em que palavras dicionarizadas têm suas entradas marcadas como neologismos? Se uma palavra é dicionarizada e marcada como neológica, ela permanece como tal? Ou sua dicionarização é (paradoxalmente) um indicativo de que não é mais um neologismo, retomando o que foi posto por Rio-Torto (2007)? Quando um neologismo é dicionarizado, em que momento ele o deixa de ser? Qual(is) o(s) critério(s) indicaria(m) a passagem de um neologismo como já sendo de uso corrente na/da língua e em que momento essa adequação deveria ser feita, especialmente em dicionários eletrônicos, cuja base de dados é mais facilmente ajustável que os impressos?

Ao ser entrevistado sobre critérios para orientar lexicógrafos na inserção de neologismos em dicionários, José Horta Nunes propõe que um caminho "produtivo para o tratamento dos neologismos [em dicionários] é o de considerar sua dimensão processual, ou seja, levar em consideração o processo de inserção e de generalização do neologismo na língua" (XATARA; BEVILACQUA; HUMBLÉ, 2011, p. 69, acréscimo nosso). Essa possibilidade de dicionarização de neologismos, ainda que produtiva, tampouco deixa de suscitar novas questões, como a dificuldade de se mapear o modo pelo qual se daria esse "processo de inserção" de uma unidade lexical na língua. Isso poderia ser feito, por exemplo, a partir de registros escritos, normalmente mais acessíveis à pesquisa. Como proceder, porém, em unidades lexicais características da oralidade?

Para tentar designar o que considera como neologismo, Cano (2007) recorre a Alain Rey (1976) para afirmar que:

A formação neológica, na maioria dos casos, não resulta de uma criação de radicais ou de afixos, ao contrário, resulta de radicais e de afixos já disponíveis no sistema, que são relacionados de uma maneira até então não observada. (REY, 1976, p. 3 apud CANO, 2007, p. 139, grifo da autora).

Assim, a maioria das formações neológicas ocorreria estabelecendo-se novas relações entre radicais e afixos, em um processo que se assemelharia ao de formação de palavras. Cano (2007) defende que essa nova relação entre elementos (radicais e afixos) já existentes caracteriza um neologismo autêntico. A nosso ver, tal posição suscita mais questões. Ao caracterizar um processo de criação neológica como "autêntico", isso torna outros processos diversos como "não autênticos" (ou ilegítimos)? Seguindo esse raciocínio, como classificar, então, palavras ex-nihilo que, em essência, são "mais autênticas" no sentido de não se basearem em formas já disponíveis no sistema linguístico? 
Na tentativa de delimitar as fronteiras para a identificação de neologismos, percebe-se que há no campo dos estudos lexicológicos certa dificuldade de estabelecê-las com precisão. Tão complexa quanto a definição do termo pode ser sua formação. O que "motiva", por exemplo, palavras ex-nihilo? Ou, como é que, a partir de recursos já existentes no sistema linguístico, outras combinações ocorrem?

Partindo dessa problematização, decidimos observar a formação neológica sob a perspectiva de um processo de formação de palavras que pode ser produtivo nesse aspecto. Especificamente, direcionaremos nosso olhar para um processo de formação de palavras considerado como marginalizado (GONÇALVES, 2012): os blends lexicais.

O blend (ou cruzamento vocabular) é, segundo Gonçalves (2006), a mistura de partes aleatórias de lexemas já existentes e que refletem suas palavras-matrizes. Nele,

a combinação de palavras promove ruptura na ordem linear estrita por meio de um overlapping, que leva a uma correspondência de um-para-muitos entre forma de base e forma cruzada. Como resultado, uma das bases é realizada simultaneamente com uma parte da outra. (GONÇALVES, 2006, p. 233).

Por consistirem de dois elementos, os blends assemelhamse a palavras compostas, diferindo delas por não possuírem em seus constituintes morfemas plenos, mas recortes de lexemas, como chafé (chá + café = café muito fraco, café que se parece com um chá). São comumente utilizados em textos literários, jornalísticos e publicitários com o fim de chamar a atenção e, por isso, tendem a ser efêmeros.

Gonçalves (2003) também explica que, no português brasileiro, há dois padrões de blend: (a) casos em que as duas palavras do blend são totalmente diferentes considerando-se seus segmentos, por exemplo, portunhol (português + espanhol = mistura de português e espanhol ou a interferência entre essas duas línguas); e (b) casos em que as duas palavras do blend apresentação algum tipo de semelhança fônica, por exemplo, politicanagem (política + sacanagem = referência à corrupção/ sacanagem na política e/ou dos políticos), como demonstrado no esquema do Quadro 1. 
v. 9 (3)

$38-56$

set-dez

2019
Quadro 1 - Blend lexical politicanagem

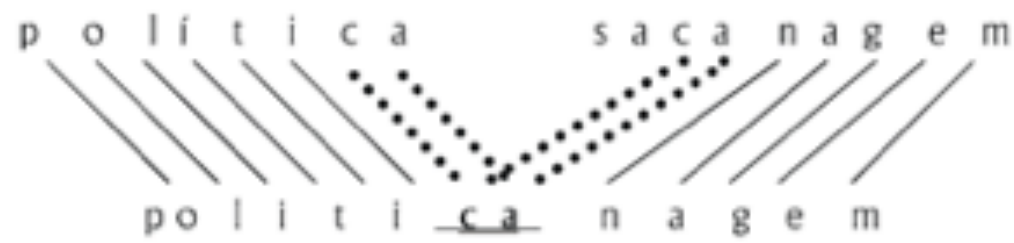

Fonte: Gonçalves (2003), p. 153

Nota-se que em politicanagem a semelhança fônica está na sílaba "ca", comum às palavras política e sacanagem, sendo tal semelhança o que determina o ponto de quebra. Dentre esses dois padrões de blend lexical do português brasileiro, este último é o que encontraremos nas ocorrências entre o termo crente e outras palavras, conforme a análise a seguir.

\section{Análise e discussão de um processo de formação neológica}

Nesta breve análise, faremos uso, como sugerem alguns dos autores citados, de um corpus de exclusão tendo como base a palavra crente. Para isso, selecionamos dois dicionários: o Dicionário Houaiss da língua portuguesa (doravante Houaiss), publicado em 2001 (HOUAISS; VILLAR; FRANCO, 2001), e o Dicionário de usos do português do Brasil (doravante DUP), de 2002 (BORBA et al, 2002). Ambos, representativos no que diz respeito ao português brasileiro, foram publicados anteriormente ao corpus de análise e em anos próximos, evitando que, de certa maneira, as definições apresentadas difiram por uma razão temporal.

Apresentamos a seguir a entrada de crente desses dois dicionários, primeiramente no Houaiss e, logo em seguida, no DUP:

crente adj.2g.s.2g $\mathbf{1}$ que ou o que crê (estava c. de que conseguiria aquele emprego) 1.1 REL que ou o que manifesta crença e/ou é sectário de uma fé religiosa (Deus se revelou a todos os C.) $\mathbf{1 . 2}$ REL $B$ que ou o que se filia a uma religião protestante, esp. as mais populares, apresentando-se austero e dispondose ger. a fazer proselitismo; bíblia 1.3 REL que ou o que segue os fundamentos do islamismo; que ou quem é devoto muçulmano 2 p.ext. B que ou o que leva excessivamente a sério suas obrigações ou assuntos, mostrando para com estes ou aquelas demasiado zelo, entusiasmo e posição acrítica 3 p.ext $B$ que ou o que é crédulo, ingênuo (é um c., acredita em tudo o que lhe dizem) [...] 
crente Adj [Qualificador de nome humano] [Compl: $\underline{\text { de+nome }}$ abstrato] 1 que segue, que obedece: um dos jogadores da seleção nacional, crente das leis de umbanda (TAF) [Compl: $\underline{\text { de+nome }}$ abstrato] 2 que dá crédito; convencido: o público, comovido, ainda crente na moralidade daquele rasgo (AV); Ainda não estou crente nas tuas palavras (CA) [Compl: oração] 3 certo; convencido; convicto: Todo mundo estava crente que eu estava tísico (RE); 0 teu mano está crente que a velha morreu $(\mathrm{RV}) \cdot \mathbf{4}$ protestante das igrejas renovadas: Seu Josafá é crente (R); um leigo católico e um crente pentecostal (PEN) $\mathbf{5}$ pessoa que segue fielmente uma religião; fiel: Quando o último crente saiu e o sacristão começou a apagar as luzes, Chico escondeu-se sob o banco (FAN); milhões de crentes beijaram sua [da Caaba] pedra sagrada (ISL) 6 criatura; pessoa: conforme o tempo que faz e o estado de alma do crente (SA); pra se fazer tratantagem somente quando a gente é andejo, porque não para em lugar nenhum, e, quando o crente dá fé, a gente


em alguma coisa: Conhece-se o crente dos milagres pela sua tendência (CRU)

Destacamos que, das definições dadas, interessa-nos a 1.2, do Houaiss, e a 4, do DUP. Ambas dizem respeito ao indivíduo seguidor de religião de base protestante, também denominado como evangélico, especificamente de "igrejas renovadas" (cf. DUP) ou "mais populares" (cf. Houaiss), condizendo com a acepção de crente que selecionamos para a análise posterior.

Seguindo o que é posto por Alves (2007) e Rio-Torto (2007), notamos que a palavra crente está dicionarizada nesse corpus de exclusão e, por não estar marcada como neologismo, concluímos ser de uso corrente por parte dos usuários da língua. Por não haver nenhuma outra entrada de unidades lexicais a partir de crente (como palavras derivadas), podemos afirmar que, caso hajam, podem ser consideradas como neologismos, de acordo com mesmas autoras.

O primeiro caso de blend é o da palavra crentice (ou crentisse):

$[1]$ 
v. 9 (3)

$38-56$

set-dez

2019
$[2]$

o meu sensor de fariseu explodiu, pega suas crentices e vai pra ONDE DEUS TE REVELAR
[3]

[4]

[5]

[6]
18 Jul 2013

Nada como acordar com um crente desconhecido gritando crentices as 7 da manhã.

na boa @gondimricardo vc tem "saco de elefante" pra aguentar esses "crentes" kkkk prefiro ficar só com Jesus e o Evangelho sem "crentices"!

estas \#crentices de membros e pastores das igrejas me deixam mto grilado, meu DEUUUSS..sou crente mas num sou xato!aff

odeio essas caretices da minha maae.Eh a crentisse. Veste uma saia jeans tambem maae!

Esses exemplos trazem o blend de crente com palavras terminadas em -ice. Ainda que os sentidos desses exemplos possam se sobrepor, sugerimos os seguintes:

- em [1]: crente + cretinice, para designar "cretinices de crentes; atos cretinos realizados por crentes";

- em [2] e [3]: crente + idiotice, para designar "idiotices de crente; atos idiotas realizados por crentes";

- em [4] e [5]: crente + chatice, para designar "chatices de crentes; atos de crentes que incomodam";

- em [6]: crente + caretice, para designar "caretice de crente" ou "posicionamentos ou atitudes caretas de crentes".

Todos esses casos estão dentro do mesmo campo semântico, visto que -ice em chatice, idiotice, cretinice e caretice acrescenta a elementos semanticamente já negativos (chato, idiota, cretino, careta) uma conotação pejorativa. O mesmo processo é observável nas palavras tolice, bobice, ranhetice, entre outras.

Por uma questão de ordem fonológica, notamos também a ocorrência da grafia crentisse. Na norma padrão, -isse é usado em verbos no pretérito imperfeito do modo subjuntivo (vogal temática de terceira conjugação - $i$ - acrescida da desinência modo-temporal 
-sse, por exemplo. em saísse, partisse, dormisse), não com substantivos como os já citados. Esse ponto sobre como o processo de formação de palavras deve seguir os mesmos critérios regulares na/da língua não passou despercebido por um dos usuários do Twitter, ainda que de forma inconsciente.

A postagem [7] questiona qual grafia seria a adequada, um indicativo de que crentice deveria ser grafada à semelhança de outras palavras no português brasileiro.

[7]

crentisse ou crentice?

\section{Outro caso:}

[8]

[9]

$\int \mathcal{J} \int \delta$ Vc é crentelho... mais chato que um militante do PT. Somente Deus pra ter

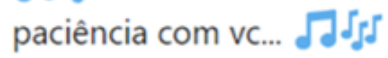

西

18 Jul 2014

qualquer coisa de ruim que acontece os crentelho fala, "jesus ta voltando", aja paciência

[10]

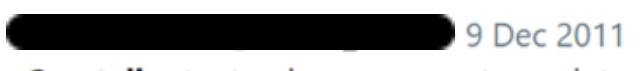

Crentelho tentando nos converter na internet já é chato, imaginem isso pessoalmente.

$[11]$

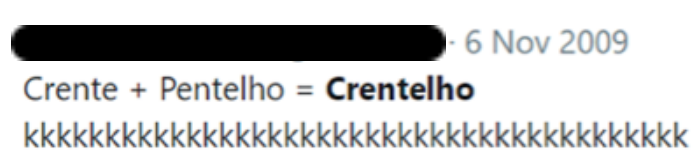

Temos aqui um caso de blend de crente + pentelho (cf. postagem [11]), para designar "crente que importuna, que não deixa aos outros em paz". Nos casos acima, o evangélico é considerado como inoportuno quando é mais incômodo que militante político (postagem [8]), quando repete bordões do tipo "Jesus está voltando" ([9]), ou quando faz proselitismo religioso, quer pessoalmente, quer no mundo virtual ([10]).

Observemos mais um exemplo:

[12]

hmm kkk vou aqui fazer merda beijar quem eu quiser dar pra quem eu bem entender e depois vou crentelhar e tentar dar discurssinho religioso pra cima de todo mundo bancando a missionária

[13] 
v. 9 (3)

$38-56$

set-dez 2019
[14]

[15] aff esses crente no facebook, quer crentelhar vai pra outro lugar, facebook não é igreja

Replying to @JinGalado

@ShaoranLi_ ninguem tem direito de pentelhar ou crentelhar ninguem..ja dizia o ditado..kk

Aqui, temos o blend de crente + pentelhar para exprimir ações exercidas por um crentelho ("crente inoportuno"), isto é, causar aborrecimento ou incômodo; importunar, chatear. Também é interessante notar que crentelhar, mesmo sendo um blend, segue o mesmo processo de formação de verbos a partir de substantivos comuns ao português brasileiro, como em espelho/espelhar, aparelho/aparelhar e enrosco/enroscar $([\mathrm{X}-\mathrm{O}]+-$-ar). Enquanto verbo regular de primeira conjugação, crentelhar possui as mesmas conjugações e formas nominais de outros verbos semelhantes:

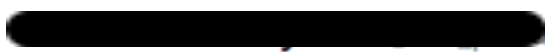

2 Oct 2015

Replying to @desistiutoda

@perbastet_crentelharam o chapolin kkk chapolin crentelhado kkk

[17]

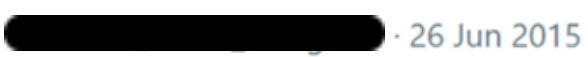

Nada contra quem é crente... Até tenho amigos crentes. Só não gosto que eles fiquem crentelhando por aí

[18]

@MTCanuto te crentelharam ai?

[19]

21 Oct 2013

63 Crentelhos e acho que iso numero vai subir. Porque Crentelhos sempre crentelharão. (@YouTube youtu.be/MD5XG3qJaTw?a)

[20]

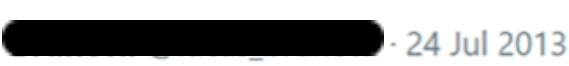

crentelhos ... pq crentelham minha t?

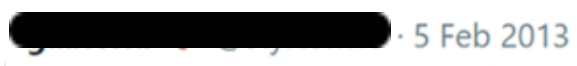

@shallon_adonai deus tá rindo da tua cara agora ahehauehaue já crentelhou hoje?

Outra ocorrência de blend: 
[22]

Sep 27

É muito incoerente a crentalha votar no bolsonaro sendo q tem o cabo daciolo

\section{Euja nato 11 Oct 2017}

Eu já não sei mais se eu lamento ou digo 'bem feito' para os cariocas que elegeram um crentalha e aproveitador da fé alheia como prefeito.

[24]

[25]

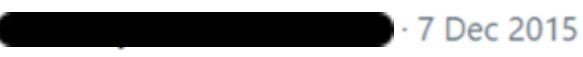

- Não se misture com essa crentalha tesouro!

- Sim mamãe!

- Crentalha, crentalha

$[25]$

\footnotetext{
. 17 Jul 2012

A CRENTALHA (CRENTE+CANALHA), não perde tempo. Ô gentinha arrogante! (@YouTube youtu.be/xbRRiyjP7il?a)
}

Nesses exemplos, observamos a ocorrência do blend crentalha. Duas possibilidades de formulação:

em [24]: crente + gentalha, para designar "crente enquanto pessoa desqualificada; alguém de baixa estirpe". Isso fica claro pela construção da postagem, que remete interdiscursivamente (no sentido pecheuxtiano) à personagem Dna. Florinda da produção mexicana "Chaves", cujo bordão era "Não se misture com essa gentalha", repetido em seguida por Quico, seu filho no seriado.

em [25]: crente + canalha (como explicitado na própria postagem) para designar "crente mau-caráter; crente que comete ações desprezíveis."

Em [22] e [23], é possível atribuir qualquer um dos dois sentidos acima à crentalha. Também vale ressaltar que esse blend pode ser usado tanto para se referir aos evangélicos enquanto indivíduos (postagens [23] e [24], a primeira em referência a Marcelo Crivella, bispo da denominação evangélica Igreja Universal do Reino de Deus e que assumiu a prefeitura do Rio de Janeiro em 2017) ou em sua coletividade, enquanto grupo social (postagens [22] e [25]).

Os exemplos a seguir trazem um caso curioso:

Posso receber com flechadas a crentalhada neopentecostal que tentará me converter ano que vem?

[27]

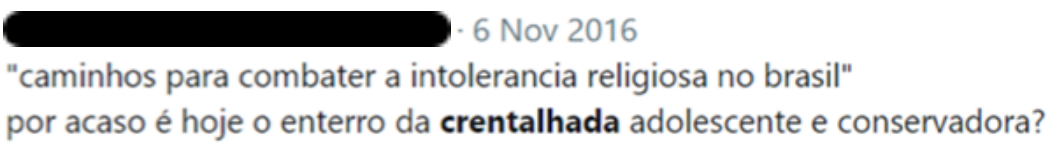


v. 9 (3)

$38-56$

set-dez

2019

[28]

[29]

ja não basta essa crentalhada enxer o meu saco tentando me converter, ainda querem cagar com o transito de belém $\neg\urcorner$ \#centenariosucks

Em crentalhada, observamos uma ocorrência de blend a partir de outro blend (crentelho +t cambada). Neste caso, há um acúmulo de sentidos para designar "bando/corja de crentes maus-caracteres; que cometem ações desprezíveis". Diferentemente de crentalha, crentalhada se refere somente ao coletivo, não ao evangélico individualmente e, pelo acréscimo semântico de cambada ("grupo ou bando de indivíduos maus"), possui um tom mais pejorativo que crentalha.

Os dois últimos casos de blend não se referem às pessoas que professam a fé evangélica em si, mas dizem respeito a esse universo. Primeiramente, apresentamos o blend crentão (crente + quentão):

[30]

52

[31]

[33]

[34]

[35]

VEI KKKKKKKKLKK fizeram uma festa junina evangélica que fizeram um quentão sem álcool e chamaram de CRENTAO ai eu to berrando

2 Jul 2016

Pastor me fez beber um chá chamado Crentão, pensem num chá ardido

18 May 2011

Na festa caipira no lugar de QUENTÃO vai ter O "CRENTÃO" pra beber kkkcoisa do grêmio rsrs tá aí o cartaz! http://twitpic.com/4zbsea

A seguir, o blend de vinho crente (vinho quente + crente):

Acabo de ler uma matéria no Uol sobre Festa Juninas evangélica, sem Santo

Antônio e São João. Ah... tem Vinho Crente (sem álcool)

\#VemLogoAsteróideDoApocalipse \#IntervençãoAlienígenaJÁ

Replying to @celio_gomes

@celio_gomes arraial gospel tem vinho crente e crentão

. 30 Aug 2010

Fui em ma quermesse evangélica, me ofereceram "Crentão" e vinho " Crente" , achei irado . 
Esses casos referem-se a duas bebidas tradicionalmente associadas às festividades juninas, o quentão e o vinho quente. Ambas devem ser evitadas, conforme o imaginário do discurso dos evangélicos, por conterem bebidas alcoólicas em sua composição. Assim, formularamse receitas próximas às originais, porém sem o acréscimo de aguardente e vinho. Crentão e vinho crente tornam-se, assim "quentão de crente; quentão que crente pode beber" e "vinho quente de crente; vinho quente que crente pode beber".

A partir da apresentação e análise desses blends lexicais cuja base é a palavra crente, pudemos observar como o processo de blend pode ser produtivo no que diz respeito à produção de palavras e sentidos a partir de outros já existentes na língua. Cabem neste momento algumas considerações sobre a possibilidade de os blends crentice/crentisse, crentelho, crentelhar, crentalha, crentalhada, crentão, vinho crente serem considerados como neologismos (ou não) ${ }^{3}$.

Primeiramente, considerando a questão temporal, como propõem Guilbert e Boulanger (respectivamente 1975 e 1979 apud ALVES, 2001), teremos dificuldade em precisar se esses blends devem ser tidos como neologismos. As amostras selecionadas para este trabalho possuem um intervalo de tempo de aproximadamente uma década (as primeiras postagens datam de 2009 e 2010). Entretanto, dado que este trabalho utiliza apenas postagens do Twitter, lançado nos Estados Unidos em 2006 e popularizado no Brasil mais tarde, haveria a possibilidade de encontrar registros desses blends em datas anteriores se tivéssemos adotado outro corpus ${ }^{4}$. De qualquer forma, o período de uma década legitima essas palavras como "novas unidades lexicais", "criações recentes" ou "novas acepções", conforme propõem os autores? Se sim, seriam, logo, neologismos. Se não, seriam de uso corrente na língua e, portanto, deveriam ter sido dicionarizadas (?).

Isso nos leva a outro ponto, a saber, à proposta metodológica de Alves (2007) e Rio-Torto (2007) a respeito da adoção de um corpus de exclusão para identificar se uma unidade lexical é ou não um neologismo. A não dicionarização de blends a partir de crente no corpus

\footnotetext{
${ }^{3}$ Concordamos que esses casos deveriam ser analisados separadamente. No entanto, por todos terem sido registrados em um intervalo de tempo mais ou menos equivalente e retirados de um mesmo corpus de análise, vamos considerá-los de forma coletiva, visto que, neste momento, nosso foco é discutir a teoria sobre a identificação de neologismos, não sobre os neologismos em si.
}

${ }^{4}$ Uma breve pesquisa em mecanismos de busca da Internet confirma que sim. 
v. 9 (3) $38-56$ set-dez 2019

de exclusão deste trabalho ${ }^{5}$ significaria que são neologismos. Por outro lado, nem todos os blends costumam ser dicionarizados. Aborrecente (aborrece + adolescente), por exemplo, possui uma entrada na versão online do Michaelis Dicionário Brasileiro da Língua Portuguesa ${ }^{6}$ como um coloquialismo, mas não é registrado na versão online do Houaiss, apenas para citar dois dicionários eletrônicos. Dessa forma, torna-se difícil precisar se crentice, crentelho etc. não foram dicionarizados por serem blends - e, portanto, por seu caráter informal/coloquial - ou por serem neologismos.

Em outra observação a respeito da teorização sobre formações neológicas, podemos afirmar que os blends a partir da palavra crente não seriam neologismos autênticos partindo da proposta de Cano (2007), que defende que autênticos são os neologismos resultantes de uma relação ainda não observada entre radicais e afixos já disponíveis no sistema. A dificuldade, nesse caso, está no uso da terminologia "autêntico", podendo sugerir que outros neologismos são, como já dito, "não autênticos" ou ainda "ilegítimos".

Por fim, tomando a posição de José Horta Nunes (XATARA; BEVILACQUA; HUMBLÉ, 2011), para quem a dicionarização de neologismos deve considerar tanto seu processo de inserção quanto de generalização na língua, precisaríamos aprofundar a pesquisa analisando um corpus mais abrangente contendo, por exemplo, textos de jornais e revistas de grande circulação e registros orais de diversas fontes. Só assim seria possível observarmos se os blends apresentados, apesar de possuírem registros abrangendo o período de uma década, possuiriam uso difundido na língua, justificando a necessidade de dicionarização, ou se estariam restritos a nichos específicos - no caso deste trabalho, às redes sociais - justificando, assim, sua não dicionarização.

\section{Considerações finais}

A partir da análise desenvolvida, pudemos perceber como os blends lexicais, enquanto processo de formação de palavras, possibilitam abundância de produção de novas palavras no português brasileiro e, com elas, novos sentidos, como defendido por Gonçalves (2012). Isso ficou

\footnotetext{
${ }^{5}$ Para efeitos de comparação, a versão eletrônica do dicionário Houaiss (disponível em: https:// houaiss.uol.com.br), atualizada em relação à impressa, tampouco registra esses blends. O DUP não possui base eletrônica.

${ }^{6}$ Disponível em: <https://michaelis.uol.com.br/moderno-portugues/busca/portugues-brasileiro/ aborrecente/>. Acesso em: 30 nov. 2018.
} 
evidenciado pelo fato de que, ao tomarmos por base uma única palavra (crente), diferentes possibilidades de associações foram encontradas, o que pode sugerir que, de maneira análoga, encontraríamos resultados ainda mais expressivos se considerássemos um número maior de palavras-matriz.

Por outro lado, seguindo as posições teórico-metodológicas disponíveis no campo lexicológico a respeito da identificação e dicionarização de neologismos, encontramos dificuldades em precisar se esses blends lexicais poderiam ou não ser considerados como tais. De modo geral, essas dificuldades consistem no fato das definições apresentadas não serem transparentes em precisar quando e sob quais condições uma determinada palavra pode ser tida como uma formação neológica. Isso acontece porque, ao tentarem recobrir determinados aspectos que poderiam, em tese, indicar uma formação neológica, as posições teóricas apresentadas suscitam outras questões sem, no entanto, darem conta delas.

Concluímos, então, que são necessários novos olhares a respeito da teorização na tentativa de se definir neologismos, dado que as posições existentes apresentam dificuldades em precisar fenômenos neológicos, o que facilitaria, deste modo, a classificação de processos recorrentes na formação de palavras no português brasileiro, como os blends lexicais.

\section{Referências}

ALVES, I. M. O conceito de neologia: da descrição lexical à planificação linguística. Alfa: Revista de Linguística, v. 40, p. 11-16, 1996.

Neologia e tecnoletos. In: OLIVEIRA, A. M. P. P. de; ISQUERDO, A. N. (Orgs.) As ciências do léxico: lexicologia, lexicografia, terminologia. 2. ed. Campo Grande, MS: UFMS, 2001. p. 25-31.

Neologia e níveis de análise linguística. In: ISQUERDO, A. N.; ALVES, I. M. (Orgs.) As ciências do léxico: lexicologia, lexicografia, terminologia. Vol. III. Campo Grandet: Humanitas, 2007. p. 77-91.

BASÍLIO, M. Teoria lexical. 7. ed. São Paulo: Ática, 2004.

BORBA, F. S. et al. Dicionário de usos do português do Brasil. São Paulo: Ática, 2002.

CANO, W. M. Tentativa de caracterização do neologismo: alguns critérios. In: ISQUERDO, A. N.; ALVES, I. M. (Orgs.) As ciências do léxico: lexicologia, lexicografia, terminologia. Vol. III. Campo Grande, MS: Humanitas, 2007. p. $137-145$. 
V. 9 (3)

$38-56$

set-dez 2019
GONÇALVES, C. A. Blends lexicais em português: não-concatenatividade e correspondência. Veredas, Rev. Est. Ling., Juiz de Fora v.7, n.1 e n.2, p.149167, jan./dez. 2003.

Usos morfológicos: os processos marginais de formação de palavras em português. Gragoatá, v. 11, n. 21, p. 219-241, 2006.

Atuais tendências em formação de palavras no português brasileiro. Signum: Estudos da Linguagem, v. 15, n. 1, p. 169-199, 2012.

HOUAISS, A.; VILLAR, M.; FRANCO, F. M. M. Dicionário Houaiss da língua portuguesa. Rio de Janeiro: Objetiva, 2001.

REY, A. Néologisme, un pseudo-concept? Cahiers de Lexicologie. Paris, v. 28, n. 1, p. 3-17, 1976.

RIO-TORTO, G. Caminhos de renovação lexical: fronteiras do possível. In: ISQUERDO, A. N.; ALVES, I. M. (Orgs.) As ciências do léxico: lexicologia, lexicografia, terminologia. Vol. III. Campo Grande, MS: Humanitas, 2007. p. $23-40$.

XATARA, C.; BEVILACQUA, C. R.; HUMBLÉ, P. R. M. (Orgs). Dicionários na teoria e na prática: como e para quem são feitos. São Paulo: Parábola Editorial, 2011. 